\title{
Predicting axillary sentinel node status in patients with primary breast cancer
}

\author{
D. KOLARIK ${ }^{1}$, V. PECHA ${ }^{2}$, M. SKOVAJSOVA ${ }^{3}$, J. ZAHUMENSKY ${ }^{4}$, M. TRNKOVA ${ }^{5}$, L. PETRUZELKA ${ }^{6}$, M. HALASKA ${ }^{7}$, O. SOTTNER ${ }^{8}$, \\ M. OTCENASEK ${ }^{9}$, H. KOLAROVA ${ }^{10}$
}

${ }^{1}$ First Faculty of Medicine, Charles University in Prague, Czech Republic; ${ }^{2}$ Department of Oncosurgery, Medicon s.r.o., Prague, Czech Republic; ${ }^{3}$ Breast Unit Prague, Prague, Czech Republic; ${ }^{4}$ Department of gynecology and obstetrics, Third Faculty of Medicine, Teaching hospital Kralovske Vinohrady, Charles University in Prague, Czech Republic; ${ }^{5}$ Biolab Praha s.r.o., Prague, Czech Republic; ${ }^{6}$ Department of Oncology, First Faculty of Medicine, General Teaching Hospital, Charles University in Prague, Czech Republic; ${ }^{7}$ Department of gynecology and obstetrics, First Faculty of Medicine, Hospital Na Bulovce, Charles University in Prague, Czech Republic; ${ }^{8}$ Department of gynecology and obstetrics, First Faculty of Medicine, Hospital Na Bulovce, Charles University in Prague, Czech Republic; ${ }^{9}$ Department of gynecology and obstetrics, First Faculty of Medicine, Hospital Na Bulovce, Charles University in Prague, Czech Republic; ${ }^{10}$ Institute of Applied Mathematics and Information Technologies, Faculty of Natural Sciences, Charles University in Prague, Czech Republic

*Correspondence: kolarikd@centrum.cz

Received August 7, 2012 / Accepted December 1, 2012

\begin{abstract}
The aim of this study is to determine the combination of characteristics in early breast cancer that could estimate the risk of occurrence of metastatic cells in axillary sentinel lymph node(s). If we were able to reliably predict the presence or absence of axillary sentinel involvement, we could spare a considerable proportion of patients from axillary surgery without compromising therapeutic outcomes of their disease. The study is based on retrospective analysis of medical records of 170 patients diagnosed with primary breast cancer. These women underwent primary surgery of the breast and axilla in which at least one sentinel lymph node was obtained. Logistic regression has been employed to construct a model predicting axillary sentinel lymph node involvement using preoperative and postoperative tumor characteristics. Postoperative model uses tumor features obtained from definitive histology samples. Its predictive capability expressed by receiver operating characteristic curve is good, area under curve (AUC) equals to 0.78 . The comparison between preoperative and postoperative results showed the only significant differences in values of histopathological grading; we have considered grading not reliably stated before surgery. In preoperative model only the characteristics available and reliably stated at the time of diagnoses were used. The predictive capability of this model is only fair when using the data available at the time of diagnosis (AUC $=0.66$ ). We conclude, that predictive models based on postoperative values enable to reliably estimate the likelihood of occurrence of axillary sentinel node(s) metastases. This can be used in clinical practice in case surgical procedure is divided into two steps, breast surgery first and axillary surgery thereafter. Even if preoperative values were not significantly different from postoperative ones (except for grading), the preoperative model predictive capability is lower compared to postoperative values. The reason for this worse prediction was identified in imperfect preoperative diagnostic.
\end{abstract}

Key words: breast cancer, tumor characteristics, sentinel node metastasis, preoperative diagnosis, postoperative diagnosis, predictive model

Prognostic and predictive characteristics of primary tumor enable estimation of the prognosis and implementation of adequate treatment in early breast cancer patients $[1,2]$. The independent prognostic value has been repeatedly proven for tumor size, histopathological grade, and lymph node status [3]. Other studies also attribute this prognostic value to HER2 $[4,5]$. Axillary lymph node status is the most important independent prognostic factor for disease free survival as well as for overall survival in breast cancer patients [6,7]. The only reliable way so far to verify the lymph node status is by microscopic examination of dissected lymph nodes. Sentinel lymph node biopsy is a widely accepted alternative for complete axillary dissection in early breast cancer $[8,9]$. Although the complication rates of this procedure are considerably lower than those of standard axillary dissection, this surgery can often be considered unnecessary as in the majority of early breast cancer cases all examined lymph nodes are without metastatic involvement. For this reason, less invasive alternative methods 
of axillary nodal evaluation are being sought. As imaging methods did not attain adequate sensitivity, some authors have attempted to calculate the risk of axillary involvement based on a combination of patient's and tumor characteristics. The rationale for this approach can be found in literature. A direct correlation between the size of the primary tumor and the incidence of axillary metastases has repeatedly been proven [10-12]. Other tumor characteristics used for indication of adjuvant therapy [13-15] have also been found useful for improving the accuracy of assessing the risk of axillary lymph node involvement. Based on this knowledge, various mathematical models have been constructed. They calculate either the risk of any axillary lymph node involvement in early breast cancer [16], or try to predict the occurrence of metastasis in additional node(s) in the case of the sentinel lymph node being affected [17-20]; the overview of the characteristics of these models is given in table 1 .

The design of our study is different from the previous ones. It deals with sentinel axillary node instead of any axillary lymph node involvement. The aim of this study thus, is to determine the combination of characteristics in early breast cancer that could estimate the risk of occurrence of metastatic cells in axillary sentinel lymph node(s). If this prediction were reliable, we could spare a considerable proportion of patients' axillary surgery without compromising therapeutic outcomes of their disease.

\section{Patients and methods}

This trial presents a retrospective analysis of the data obtained from medical records of patients treated in a leading oncosurgical institution in Prague, Czech Republic. The study population was composed of patients diagnosed with primary breast cancer between the years 2008 to 2010 . Out of this group, 617 women underwent primary breast surgery (either breast conserving or mastectomy) followed by axillary sentinel lymph node biopsy in which at least one lymph node was obtained. The mean age at the time of diagnosis of these patients was 57.3 years. Suspicion of malignancy was ascertained from imaging methods (mammography, ultrasonography, magnetic resonance) and clinical examination. Thereafter, the diagnosis was verified by core needle biopsy. All the patients also underwent necessary staging procedures so that the exact clinical staging could be established according to the TNM system. Patients with distant metastases were excluded from the study.

Ultrasonography was considered more accurate for description of tumor extension than mammography. Lymph node status (axillary and periclavicular) has also primarily been

Table 1. The overview of the characteristics of the models predicting the affection of axillary lymph nodes.

\begin{tabular}{|c|c|c|c|c|}
\hline $\begin{array}{l}\text { author, } \\
\text { institution, } \\
\text { publ. year }\end{array}$ & $\begin{array}{c}\text { number of } \\
\text { patients }\end{array}$ & statistical method & statistically significant characteristics & evaluation of predictive capability \\
\hline $\begin{array}{l}{ }^{\text {a) }} \text { Ravdin } \\
\text { NBCTR } \\
1994(16)\end{array}$ & $\begin{array}{c}11.964 \\
\text { retrospective }\end{array}$ & $\begin{array}{c}\text { stepwise MLR } \\
\text { (with or without } \\
\text { interactions of first order) }\end{array}$ & $\begin{array}{c}\text { size of primary tumor } \\
\text { S-phase fraction } \\
\text { age of the patient } \\
\text { progesterone receptors count } \\
\end{array}$ & $\begin{array}{l}\text { not allow for prediction of whether a patient has } \\
\text { greater than } 95 \% \text { chance of being node positive } \\
\text { or node negative - „cannot replace prognostic } \\
\text { information obtained with dissection of the nodes“ }\end{array}$ \\
\hline $\begin{array}{l}\text { b) van Zee } \\
\text { MSKCC } \\
2003(17)\end{array}$ & $\begin{array}{c}1.075 \\
\text { prospective }\end{array}$ & $\begin{array}{c}\text { MLR } \\
\text { ROC } \\
\text { nomogram }\end{array}$ & $\begin{array}{c}\text { definitive size of primary tumor } \\
\text { LVSI } \\
\text { number of positive SLNs } \\
\text { number of negative SLNs } \\
\text { size of lymph node metastasis }\end{array}$ & $\begin{array}{l}\text { AUC }=0.76 \\
\text { model is ,imperfect“, its results cannot directly be } \\
\text { used for the recommendations in clinical practice }\end{array}$ \\
\hline $\begin{array}{l}\text { b) Kohrt } \\
\text { Stanford } \\
2008(18)\end{array}$ & $\begin{array}{c}285 \\
\text { prospective }\end{array}$ & $\begin{array}{c}\text { MLR } \\
\text { recursive partitioning ROC } \\
\text { Classification and } \\
\text { Regression Trees } \\
\end{array}$ & $\begin{array}{c}\text { definitive size of primary tumor } \\
\text { LVSI } \\
\text { estrogen receptors count } \\
\text { size of lymph node metastasis } \\
\end{array}$ & $\begin{array}{c}\text { MLR gives best predictive results; } \\
\text { AUC }=0.85 \text { using the size, LVSI a ER status } \\
\text { AUC }=0.83 \text { using the size and LVSI } \\
\text { (MSKCC model with the same data set AUC }=0.77 \text { ) }\end{array}$ \\
\hline $\begin{array}{l}\text { b) Coufal } \\
\text { MOU Brno } \\
2009(19)\end{array}$ & $\begin{array}{l}330 \\
\text { retrospective }\end{array}$ & $\begin{array}{l}\text { univariate estimation of } \\
\text { predictive capability of } \\
\text { variables; } \\
\text { MLR (stepwise - backward) } \\
\text { ROC }\end{array}$ & $\begin{array}{l}\text { definitive size of primary tumor } \\
\text { size of lymph node metastasis extranodal } \\
\text { spread of the metastasis } \\
\text { relation of the number of positive SLNs } \\
\text { to the number of all dissected nodes }\end{array}$ & $\begin{array}{c}\mathrm{AUC}=0.76 \\
(\text { control data set from another hospital: } \mathrm{AUC}= \\
0.74)\end{array}$ \\
\hline $\begin{array}{l}\text { c) Jeruss } \\
\text { MDACC } \\
2007(20)\end{array}$ & $\begin{array}{c}104 \\
\text { prospective }\end{array}$ & $\begin{array}{c}\text { univariate estimation of } \\
\text { predictive capability of } \\
\text { variables; } \\
\text { MLR (stepwise - backward) } \\
\text { ROC } \\
\text { monogram }\end{array}$ & $\begin{array}{c}\text { definitive size of primary tumor } \\
\text { LVSI } \\
\text { multifocality } \\
\text { size of lymph node metastasis } \\
\text { LN status at the time of diagnosis }\end{array}$ & $\begin{array}{c}\mathrm{AUC}=0.76 \\
(\text { control data set from another hospital: } \mathrm{AUC}=0.78)\end{array}$ \\
\hline
\end{tabular}



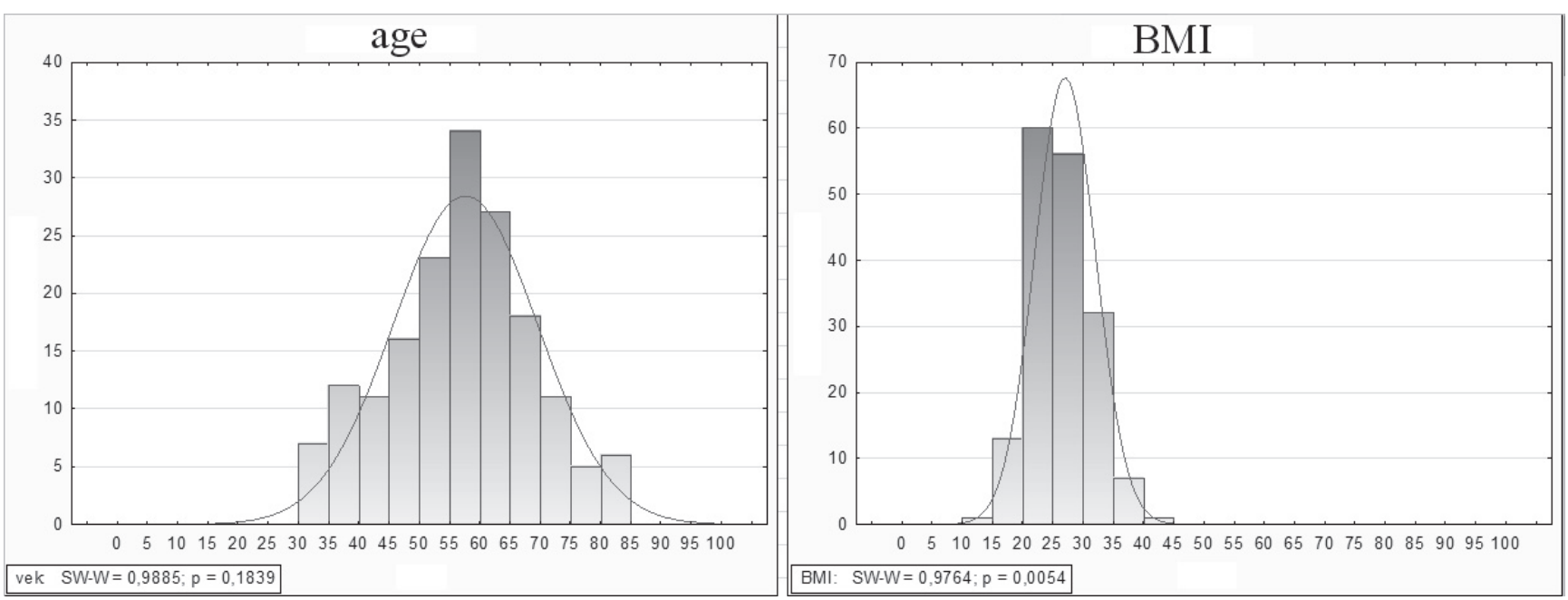

Figure 1. Histogram of the distribution of the age and body mass index of the patients. Normal Gaussian distribution is seen in the diagrams. L: BMI = body mass index

evaluated by ultrasound and physical examination. For statistical reasons, HER2 is designated as "positive" in the event of immunohistochemical 2+ or 3+ scores; otherwise, the tumor is considered as HER2 "negative". The lymphovascular space invasion (LVSI) cannot be reliably investigated preoperatively since the biopsy is directed to the center of the lesion, and LVSI must be obtained from the peripheral part of the tumor mass. Any sentinel nodes involvement was considered as "positive", irrespective of metastatic cell burden in the nodes.

Statistics. In order to minimize the potential sources for inaccuracy of statistical conclusions, the data set had to be adjusted. This adjustment was performed by the statistician for the following reasons. First, outliers have to be excluded; this also means 106 patients with in situ carcinoma had to be taken away as metastatic involvement was only found in one case this group (outlier). Second, the number of lymph node negative patients must be similar to the number of patients with affected sentinel nodes. Thus, out of the prevailing cases with negative lymph nodes, $24 \%$ of records were selected by random choice to make this group comparable to the other one. Third, some subgroups of patients had to be united so that sufficient counts were reached in all the subgroups (expected count recommended for each group is five or more). For this reason, for instance, tumors found in upper inner and lower inner quadrants were designated to be in "medial location", all the other sites were designated as "lateral location". Detailed description of the reasons for data set adjustment, however, exceeds the focus of this article and is the thesis subject of the main author [21]. Therefore, out of a study population of 617 patients, 170 were chosen to form the target population used for construction of the models.

Multivariate logistic regression was used for the calculation of a predictive model; Wald statistic was employed to estimate its parameters of the equation. Thereafter, acceptability of the model was verified with Hosmer-Lemeshow test of proper correlation of used data with regression model. Since the data obtained after the surgery more accurately reflect the real composition of the malignant tumor, we have constructed a postoperative predictive model based on definitive histological analysis (step 1). Thereafter, we analyzed the degree of discrepancies between postoperative and preoperative values to be able to identify the characteristics that were not credibly known during preoperative diagnosis (step 2). McNemara and Bowker test were used for categorical variables, Wilcox pair test and $\mathrm{t}$-test were used for continuous variables. P-value $<0.05$ was considered statistically significant. Detailed analysis of the agreement between postoperative and preoperative values is described in another article [22]. The aim of this study was to formulate the regression equation predicting axillary sentinel nodes involvement based on preoperative values (preoperative model - step 3). In this model, the same variables were used as in the postoperative model excluding those not available at the time of diagnosis and those not trustworthy at the time of diagnosis (i.e. variables with significant differences between preoperative and postoperative values). A Receiver Operating Characteristic (ROC) curve has been constructed for both models to evaluate their credibility to predict axillary sentinel nodes involvement (by its area under curve - AUC). Statistical software IBM SPSS Statistics 18 has been used.

\section{Results}

Prediction based on postoperative values ("postoperative model" - step 1). The distribution of the study population according to age and body mass index (BMI) is shown in figure 1 . The mean age at the time of diagnosis was 57.3 years (range 31-85, median 58), mean BMI was 27.7 (range 14.844.3, median 24.8). 

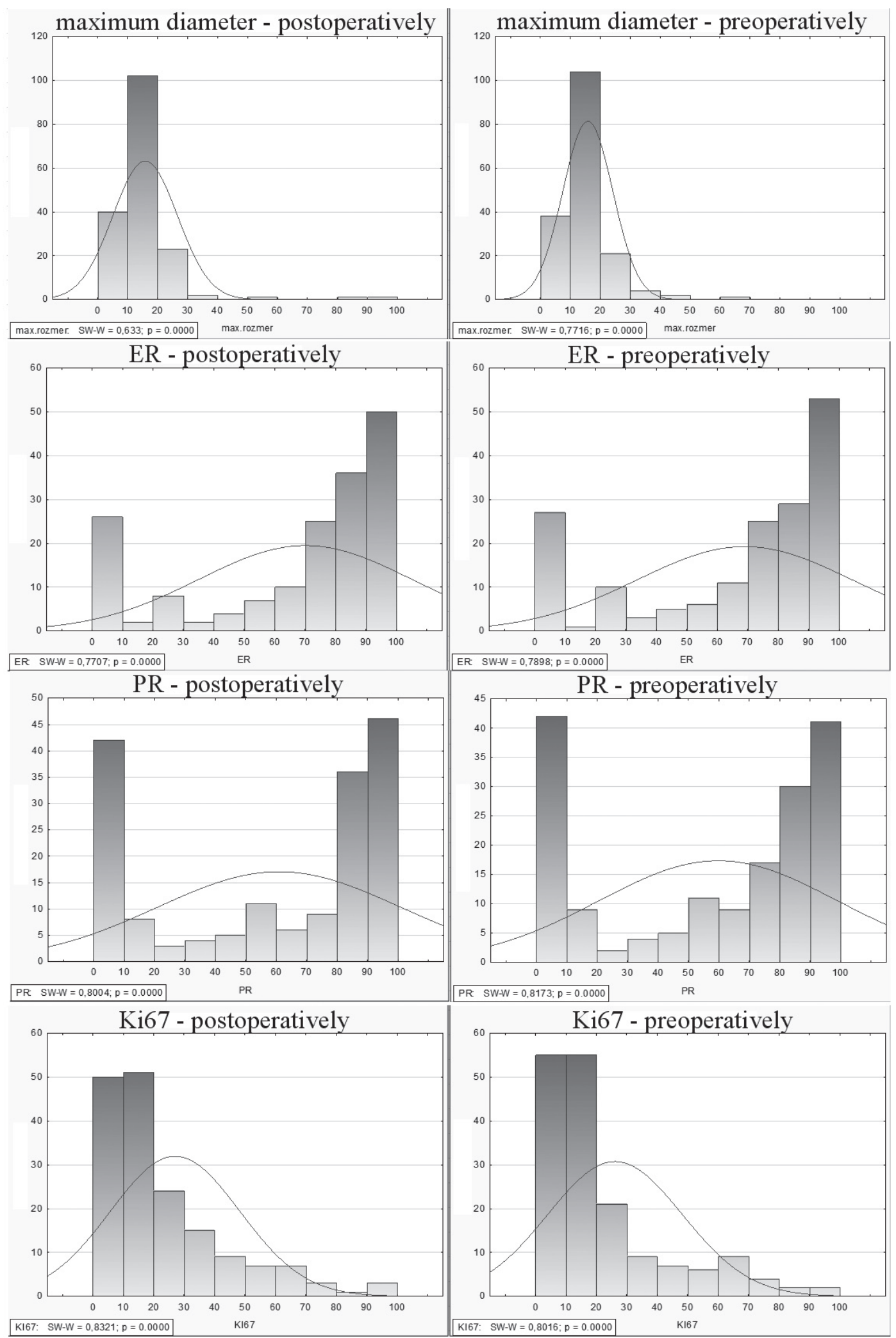

Figure 2. Comparison of postoperative and preoperative values of the continuous variables. The distribution of estrogen and progesterone receptor count is not normal, it exhibits one peak in $0 \%$ and another peak in $80-100 \%$.

$\mathrm{L}: \mathrm{ER}=$ estrogen receptors, $\mathrm{PR}=$ progesteron receptors, $\mathrm{KI} 67$ = proliferative index 


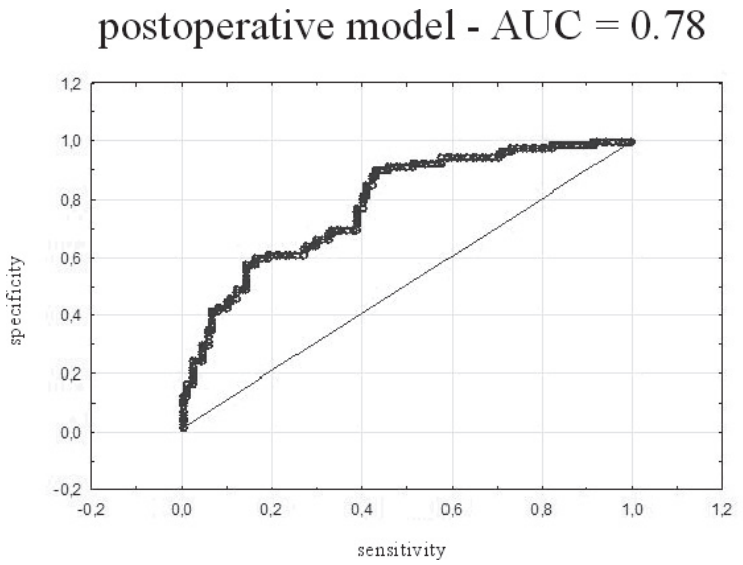

Figure 3. ROC curves for postoperative and preoperative models L: $\mathrm{ROC}=$ Receiver Operating Characteristic

Descriptive statistics of categorical variables are stated in table 2. Metastatic involvement of sentinel node was observed more frequently in the presence of LVSI, in lobular compared to ductal type and in multifocal compared to solitary lesion; less frequent metastases occurred in grade 1 compared to other grades; location of the tumor and HER2 status did not seem to influence the frequency of sentinel node affection.

The distribution of the values of continuous variables is depicted in figure 2 . More than $83 \%$ of tumors belonged to stage T1, mean maximum diameter was 16.1 millimeters; majority of tumors had proliferative activity less than $25 \%$, mean KI67 index was 17.4\%.

Postoperative logistic regression model follows:

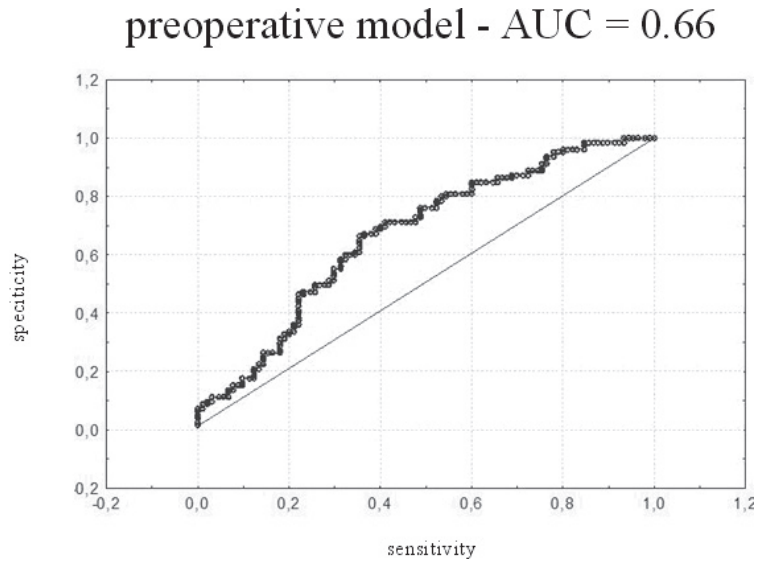

logit $($ metastasis_YES $)=-1.82-0.21^{\star}$ location $($ medial $)$ $-0.12 *$ histology $($ ductal $)+0.36 *$ surgery(hospital -1$)$ -0.39 * surgery(hospital-2) -0.33 * grade $(1)+0.18$ * grade $(2)-\mathbf{0 . 4 4}{ }^{*} \mathbf{L V S I}($ absent $)+0.26{ }^{*}$ HER2(negative) $-0.14^{\star}$ multifocality (single) $+\mathbf{0 . 1 5}{ }^{\star}$ max.diameter $-0.01 * \mathrm{ER}+\mathbf{0 . 0 1} * \mathbf{P R}-0.01 * \mathrm{KI} 67+0.01 * \mathrm{BMI}+$ $0.001 *$ age

For lymphovascular space invasion (LVSI), maximum diameter and $\mathrm{PR}$ count the $\mathrm{p}$-value $<0.05$ signalizes these characteristics are statistically significant. However, if we used only these significant variables, the sensitivity would be lower

Table 2. Descriptive statistics of categorical variables

\begin{tabular}{|c|c|c|c|c|c|c|}
\hline variable & value & $\mathbf{N}$ & metastasis YES & metastasis NO & metastasis YES \% & metastasis NO \% \\
\hline \multirow{2}{*}{ location } & medial & 62 & 28 & 34 & $45 \%$ & $55 \%$ \\
\hline & lateral & 108 & 52 & 56 & $48 \%$ & $52 \%$ \\
\hline \multirow{2}{*}{ histology } & ductal & 154 & 71 & 83 & $46 \%$ & $54 \%$ \\
\hline & lobular & 16 & 9 & 7 & $56 \%$ & $44 \%$ \\
\hline \multirow{3}{*}{ site of surgery } & hospital 1 & 63 & 32 & 31 & $51 \%$ & $49 \%$ \\
\hline & hospital 2 & 47 & 18 & 29 & $38 \%$ & $62 \%$ \\
\hline & hospital 3 & 60 & 30 & 30 & $50 \%$ & $50 \%$ \\
\hline \multirow{3}{*}{ grade } & 1 & 47 & 18 & 29 & $38 \%$ & $62 \%$ \\
\hline & 2 & 82 & 43 & 39 & $52 \%$ & $48 \%$ \\
\hline & 3 & 41 & 19 & 22 & $46 \%$ & $54 \%$ \\
\hline \multirow{2}{*}{ LVSI } & absent & 120 & 47 & 73 & $39 \%$ & $61 \%$ \\
\hline & present & 50 & 33 & 17 & $66 \%$ & $34 \%$ \\
\hline \multirow{2}{*}{ HER2 rec. } & negative & 133 & 64 & 69 & $48 \%$ & $52 \%$ \\
\hline & positive & 37 & 16 & 21 & $43 \%$ & $57 \%$ \\
\hline \multirow{2}{*}{ multifocality } & single focus & 147 & 67 & 80 & $46 \%$ & $54 \%$ \\
\hline & multiple foci & 23 & 13 & 10 & $57 \%$ & $43 \%$ \\
\hline total & & 170 & 80 & 90 & $47 \%$ & $53 \%$ \\
\hline
\end{tabular}


and the false negativity would be higher; thus, the remaining variables (not statistically significant) cannot be excluded from the model since its quality would drop substantially. Table 3 and figure 3 summarize the predictive capability of the postoperative model. Sensitivity to assess the sentinel node affection of $61 \%$ is fair; positive and negative predictive value of $73 \%$ and $70 \%$ respectively is acceptable. If these data were available at the time of diagnosis, the capability to estimate the risk of sentinel nodes involvement would be good ( $\mathrm{AUC}=0.78$ ).

Comparison between postoperative and preoperative values (step 2). Comparisons of postoperative and preoperative values of categorical variables are shown in table 4 . Preoperative determination of tumor location and histological type of the tumor reflects almost exactly the real situation verified postoperatively; preoperative assessment of HER2 status and multifocality also showed to be very reliable; obvious differences can be seen in pre- and postoperative values of tumor grading. Comparisons of continuous variables are displayed in histograms in figure 2 - the distribution of preoperative variables is very similar to that of postoperative variables. Statistical methods stated above have found that out of all the variables only the values of histopathological grading were statistically significantly different before and after surgery.

Prediction based on preoperative values ("preoperative model" - step 3). The variable "grading" had to be excluded (as its preoperative values differed significantly from postoperative values); the variable LVSI was not available preoperatively. Thus, only the remaining variables can be used for preoperative model. Only the maximum diameter of the tumor $(\mathrm{p}=$ $0,00)$ and PR count $(p=0,04)$ are statistically significant. Preoperative logistic regression equation thus, has the following form:

$\operatorname{logit}($ metastasis_YES $)=-2.24-0.23 * \operatorname{location}($ medial $)$ $+0.06^{*}$ histology $($ ductal $)+0.29 *$ surgery (hospital- 1$)-$ $0.43 *$ surgery $($ hospital -2$)+0.20 *$ HER2 (negative) -0.27 ${ }^{\star}$ multifocality (single $)+\mathbf{0 . 1 6}{ }^{*}$ max.diameter $-0.01 * \mathrm{ER}$ $+0.01 *$ PR -0.002 * KI67 $-0.02 * \mathrm{BMI}+0.005^{\star}$ age
This model still retains good predictive capability when using postoperative data. However, for the data available before surgery, this model is not acceptable (significant difference occurred between model-predicted and real values). Predictive capability of preoperative model using data available at the time of diagnosis is summarized in table 3 and figure 3 -sensitivity is as low as $53 \%$, false negativity reaches $48 \%$, positive and negative predictive values are $61 \%$ and $60 \%$ respectively. We conclude that although the data before and after surgery did not show significant differences, the model constructed on the basis of postoperative data cannot be used for preoperative data (predictive capability is only fair, $\mathrm{AUC}=0.66$ ).

\section{Discussion}

Mathematical models for axillary lymphatic involvement in breast cancer patients. Multivariate analyses have repeatedly defined axillary lymph node status as one of the most important independent prognostic factors for diseasefree survival and for overall survival of patients with breast cancer $[6,7]$. Whether or not it is possible to predict axillary lymphatic involvement without dissection of the nodes is thus a relatively old question. The question is raised by the effort to minimize the radicality of axillary surgical procedures or even to omit axillary surgery completely. However, imaging methods (including ultrasound, computed tomography and magnetic resonance) did not show acceptable sensitivity for evaluation of low-volume metastatic nodal involvement. The only non-surgical method of determination of the risk of metastatic cells presence in axillary nodes thus is the estimation based on characteristics of primary breast tumor. The aim was to define a group of patients with such a low risk of metastasis that would justify not performing axillary dissection.

In the nineties of the last century, a crucial paper dealing with this topic was published analyzing nearly 12,000 patients from the National Breast Cancer Tissue Resource database [16]. Primary tumors smaller than $5 \mathrm{~cm}$ and at least 15 histologically examined lymph nodes were the inclusion criteria of this study; stepwise multivariate regression analysis was used.

Table 3. Comparison of postoperative and preoperative regression models (their capability to estimate the risk of sentinel nodes involvement)

\begin{tabular}{|c|c|c|c|c|}
\hline & \multicolumn{2}{|c|}{ postoperative model } & \multicolumn{2}{|c|}{ preoperative model } \\
\hline & estimated metastasis_YES & estimated metastasis_NO & estimated metastasis_YES & estimated metastasis_NO \\
\hline real metastasis_YES & 49 & 31 & 42 & 38 \\
\hline real metastasis_NO & 18 & 72 & 27 & 63 \\
\hline sensitivity & \multicolumn{2}{|c|}{$61 \%$} & \multicolumn{2}{|c|}{$53 \%$} \\
\hline false positivity & \multicolumn{2}{|c|}{$20 \%$} & \multicolumn{2}{|c|}{$30 \%$} \\
\hline specificity & \multicolumn{2}{|c|}{$80 \%$} & \multicolumn{2}{|c|}{$70 \%$} \\
\hline false negativity & \multicolumn{2}{|c|}{$39 \%$} & \multicolumn{2}{|c|}{$48 \%$} \\
\hline positive predictive value & \multicolumn{2}{|c|}{$73 \%$} & \multicolumn{2}{|c|}{$61 \%$} \\
\hline negative predictive value & \multicolumn{2}{|c|}{$70 \%$} & \multicolumn{2}{|c|}{$60 \%$} \\
\hline
\end{tabular}


Table 4. Comparison between preoperative and postoperative values

\begin{tabular}{|c|c|c|c|c|c|}
\hline \multicolumn{2}{|c|}{ preoperative values } & \multicolumn{4}{|c|}{ postoperative values } \\
\hline \multirow{4}{*}{$\begin{array}{l}\text { location } \\
(p=1.00)\end{array}$} & & medial & \multicolumn{2}{|r|}{ lateral } & total \\
\hline & medial & 61 & \multicolumn{2}{|r|}{1} & 62 \\
\hline & lateral & 1 & \multicolumn{2}{|r|}{107} & 108 \\
\hline & total & 62 & \multicolumn{2}{|r|}{108} & 170 \\
\hline \multirow{4}{*}{$\begin{array}{l}\text { histology } \\
(p=0.625)\end{array}$} & & ductal & \multicolumn{2}{|r|}{ lobular } & total \\
\hline & ductal & 149 & \multicolumn{2}{|r|}{3} & 152 \\
\hline & lobular & 1 & \multicolumn{2}{|r|}{13} & 14 \\
\hline & total & 150 & \multicolumn{2}{|r|}{16} & 166 \\
\hline \multirow{5}{*}{$\begin{array}{l}\text { grading } \\
(\mathrm{p}=0.001)\end{array}$} & & 1 & 2 & 3 & total \\
\hline & 1 & 45 & 15 & 2 & 62 \\
\hline & 2 & 2 & 60 & 16 & 78 \\
\hline & 3 & 0 & 7 & 23 & 30 \\
\hline & total & 47 & 82 & 41 & 170 \\
\hline \multirow{4}{*}{$\begin{array}{l}\text { HER2 } \\
(\mathrm{p}=1.00)\end{array}$} & & negative & \multicolumn{2}{|r|}{ positive } & total \\
\hline & negative & 128 & \multicolumn{2}{|r|}{4} & 132 \\
\hline & positive & 5 & \multicolumn{2}{|r|}{33} & 38 \\
\hline & total & 133 & \multicolumn{2}{|r|}{37} & 170 \\
\hline \multirow{4}{*}{$\begin{array}{l}\text { multifocality } \\
(\mathrm{p}=1.00)\end{array}$} & & single focus & \multicolumn{2}{|r|}{ multiple foci } & total \\
\hline & single focus & 138 & \multicolumn{2}{|r|}{10} & 148 \\
\hline & multiple foci & 9 & \multicolumn{2}{|r|}{13} & 22 \\
\hline & total & 147 & \multicolumn{2}{|r|}{23} & 170 \\
\hline
\end{tabular}

Following characteristics were statistically significant for the estimation of the presence of at least one affected axillary node: size of the primary tumor, proliferation activity (Sphase fraction), age at the time of diagnosis, and the presence of progesterone receptors. The authors state that although somewhat successful predictive model can be produced to predict axillary lymph node involvement, this model does not allow for prediction of whether a patient has a greater than $95 \%$ chance of being node negative or node positive. They concluded that the model cannot replace prognostic information obtained with dissection of the nodes and their histological examination.

Introduction of sentinel lymph node (SLN) biopsy into clinical practice has lead to a significant reduction in the degree of radicality of axillary surgery. It has been proven that complete axillary dissection can be safely excluded in women with negative SLN [23]. Completion of axillary dissection was recommended only in cases with at least one positive SLN. However, even this approach appeared to be inappropriately radical as only about $35-50 \%$ of women with metastasis in SLN also had at least one non-sentinel node affected [24-28]. Thus in the majority of women with positive SLN completion of axillary dissection can be considered as inappropriate overtreatment. Efforts to restrict radicality in the axilla again opened a new area for predictive modeling. Among women with metastatic involvement of SLN, these models have tried to identify a group of patients in whom the risk of affliction on non-sentinel nodes is low so that it allows for avoidance of complete axillary clearance without negatively influencing the prognosis of the patients. These papers are important from the methodological point of view as they reflect up-to-date requirements for statistical processing of data in oncological patients.

The most often cited article for this type of prediction is the Memorial Sloan-Kettering Cancer Center model published in 2003 that analyzed 1075 cases [17]. Characteristics of lymph nodes (number of positive SLNs, number of negative SLNs, size of the metastasis) and also of primary tumors (size measured in histology specimen, LVSI) were statistically significant. The capability of the model to predict non-sentinel metastases is expressed by the area under curve $\mathrm{ROC}=0.76$; the authors consider this model as "imperfect" and emphasize that the results of the prediction cannot directly be used in clinical practice [17]. However, other papers suggest the risk estimation given by the model helps (better than expert opinion) to decide the relevance of completion of axillary dissection [18]. The characteristics of this and other models are summarized in table 1 [16-20].

Other models tried to predict affection of non-sentinel nodes in patients with histologically confirmed SLN metastasis at the time of diagnosis who received neoadjuvant chemotherapy (NACT) [20]. Authors from M.D. Anderson Cancer Center have analyzed a relatively small group of 104 patients and found statistical significance of the following characteristics: definitive size of primary tumor, LVSI, multifocality, method of detection of lymph node metastasis that roughly corresponds with the size of metastasis and clinical status of axillary nodes at the time of diagnosis. Area under ROC curve 
was 0.76 ; using the model for the data set from another hospital showed AUC $=0.78$.

Predictive models are methodologically similar: they use multivariate logistic regression, although in various modifications. Primary tumor size measured in histological specimens and LVSI are the most frequent features significant for prediction of axillary involvement. Area under ROC curve is a useful method for direct comparison of predictive capability of the models.

Results and clinical significance of our model. Our study moves forward compared to previous papers. It concentrates on sentinel axillary nodes instead of dealing with any axillary lymph nodes affection. This principal difference is given by the shift in clinical practice: nowadays, axillary sentinel lymph node dissection is the standard procedure in early breast cancer and no more lymph nodes can be obtained without obvious harm to the patients. The following postoperative characteristics were statistically significant in multivariate logistic regression: maximum diameter measured in histological specimen, LVSI and percentage of progesterone receptors. However, the variables with no proven statistical significance contribute to the predictive power of the model. The same conclusion has been drawn when constructing MSKCC [17] and MOU [19] models.

Our postoperative model used similar methods and analyzed data in a similar number of patients compared to the studies shown in table 1. Statistical significance was proven for similar characteristics, especially for primary tumor size and LVSI. Also the degree of reliability to estimate the risk of sentinel node involvement is comparable to all major predictive models published so far; this is best exemplified in ROC curves, AUC $=0.78$ (see figure 3). Thus, these models can only be used in clinical practice in the case that the surgical procedure is divided into two steps: breast surgery first, axillary surgery thereafter. Then axillary surgery can hopefully be omitted in cases with very low expected risk of sentinel node affection. From this point of view, our postoperative model has predictive capability comparable to MSKCC model that is widely used to assist clinical judgment when attempting to diminish the degree of radicality of axillary surgery [17].

Preoperative data (with the exception of grading) did not significantly differ from postoperative values. This minimal difference raised hopes of being able to predict axillary metastases based on preoperative values, i.e. in present clinical practice. After eliminating the grading and LVSI (not available before surgery) preoperative model has been constructed. Only maximum primary tumor diameter and progesterone receptor percentage remained as statistically significant variables. However, this model predicted values significantly different from the real situation. Capability of prediction is distinctly lower compared to postoperative values. This is the reason for our conclusion: imperfect preoperative diagnostic is a major problem hampering the estimation of occurrence of sentinel lymph modes metastases.

\section{Conclusion}

Predictive models constructed on the basis of detailed histopathological examination of postoperative specimens enable to estimate the likelihood of occurrence of axillary sentinel node metastases. In the case we divided the surgical procedure in two steps as stated above our model would be a useful tool in addition to clinical judgment as to whether or not to perform axillary sentinel lymph node dissection. Even if preoperative values were not significantly different from postoperative ones (except for grading), the model based on preoperative data predicted only unreliably the real risk of occurrence of axillary sentinel lymph node metastasis. Thus, entreaty to more exact preoperative diagnostic is crucial.

\section{References}

[1] WALKER RA. Prognostic and predictive factors in breast cancer. New York: Martin Dunitz, 2003.

[2] KOLARIK D, NETIKOVA L, MARINOV I, JULIS I, HALASKA,MJ et al. Breast cancer cell population and their changes during therapy. Ceska Gynekol 2006; 71: 43-60.

[3] DENLEY H, PINDER SE, ELSTON CW, LEE AH, ELLIS IO. Preoperative assessment of prognostic factors in breast cancer. J Clin Pathol 2001; 54: 20-24. http://dx.doi.org/10.1136/ icp. 54.1 .20

[4] DEPOWSKI PL, BRIEN TP, SHEEHAN CE, STYLOS R, JOHNSON RL et al. Prognostic significance of p34cdc2 cyclin-dependent kinase and MIB1 overexpression, and HER-2/neu gene amplification detected by fluorescence in situ hybridization in breast cancer. Am J Clin Pathol 1999; 112: 459-469.

[5] PRESS MF, BERNSTEIN L, THOMAS PA, MEISNER LF, ZHOU JY et al. HER-2/neu gene amplification characterized by fluorescence in situ hybridization: poor prognosis in node-negative breast carcinomas. J Clin Oncol 1997; 15: 2894-2904.

[6] BEENKEN SW, URIST MM, ZHANG Y, DESMOND R, KRONTIRAZ $\mathrm{H}$ et al. Axillary lymph node status, but not tumor size, predicts locoregional recurrence and overall survival after mastectomy for breast cancer. Ann Surg 2003; 237: 732-738. http://dx.doi.org/10.1097/01.SLA.0000065289.06765.71

[7] AMERSI F, HANSEN NM. The benefits and limitations of sentinel lymph node biopsy. Curr Treat Options Oncol 2006; 7: 141-151. http://dx.doi.org/10.1007/s11864-006-0049-y

[8] KRAG DN, ANDERSON SJ, JULIAN TB, BROWN AM, HARLOW SP et al. Technical outcomes of sentinel-lymph-node resection and conventional axillary-lymph-node dissection in patients with clinically node-negative breast cancer: results from the NSABP B-32 randomised phase III trial. Lancet Oncol 2007; 8: 881-888. http://dx.doi.org/10.1016/S14702045(07)70278-4

[9] KIM T, GIULIANO AE, LYMAN GH. Lymphatic mapping and sentinel lymph node biopsy in early-stage breast carcinoma - A metaanalysis. Cancer 2006; 106: 4-16. http://dx.doi. org/10.1002/cncr.21568 
[10] BEDROSIAN I, REYNOLDS C, MICK R, CALLANS LS, GRANT CS et al. Accuracy of sentinel lymph node biopsy in patients with large primary breast tumors. Cancer 2000; 88: 2540-2545. http://dx.doi.org/10.1002/1097-0142(20000601) 88:11<2540::AID-CNCR16>3.0.CO;2-A

[11] FERNO M. Prognostic factors in breast cancer: a brief review. Anticancer Res 1998; 18: 2167-2171.

[12] GRECO M, AGRESTI R, CASCINELLI N, CASALINI P, GIOVANAZZI R et al. Breast cancer patients treated without axillary surgery: clinical implications and biologic analysis. Ann Surg 2000; 232: 1-7. http://dx.doi.org/10.1097/00000658200007000-00001

[13] GOLDHIRSCH A, GLICK JH, GELBER RD, COATES AE, THURLIMAN B et al. Meeting highlights: international expert consensus on the primary therapy of early breast cancer 2005. Ann Oncol 2005; 16: 1569-1583. http://dx.doi.org/10.1093/ annonc/mdi326

[14] CINIERI S, ORLANDO L, FEDELE P, CUSMAI A, D'AMICO $M$. et al. Adjuvant strategies in breast cancer: new prospectives, questions and reflections at the end of 2007 St Gallen International Expert Consensus Conference. Ann Oncol 2007; 18, Suppl 6:vi63-vi65. http://dx.doi.org/10.1093/annonc/mdm227

[15] GOLDHIRSCH A, INGLE JN, GELBER RD, COATES AE, THURLIMAN B et al. Thresholds for therapies: highlights of the St Gallen International Expert Consensus on the primary therapy of early breast cancer 2009. Ann Oncol 2009; 20: 1319-1329. http://dx.doi.org/10.1093/annonc/mdp322

[16] RAVDIN PM, DE LM, VENDELY T, CLARK GM. Prediction of axillary lymph node status in breast cancer patients by use of prognostic indicators. J Natl Cancer Inst 1994; 86: 1771-1775. http://dx.doi.org/10.1093/jnci/86.23.1771

[17] VANZEE KJ, MANASSEHDM, BEVILACQUAJL, BOOLBOL SK, FEY JV et al. A nomogram for predicting the likelihood of additional nodal metastases in breast cancer patients with a positive sentinel node biopsy. Ann Surg Oncol 2003; 10: 1140-1151. http://dx.doi.org/10.1245/ASO.2003.03.015

[18] KOHRT HE, OLSHEN RA, BERMAS HR, GOODSON WH, WOOD DJ et al. New models and online calculator for predicting non-sentinel lymph node status in sentinel lymph node positive breast cancer patients. BMC Cancer 2008; 8: 66. http://dx.doi.org/10.1186/1471-2407-8-66

[19] COUFAL O, PAVLIK T, FABIAN P, BORI R, BOROSS G et al. Predicting non-sentinel lymph node status after positive sentinel biopsy in breast cancer: what model performs the best in a Czech population? Pathol Oncol Res 2009; 15: 733-740. http://dx.doi.org/10.1007/s12253-009-9177-6

[20] JERUSS JS, NEWMAN LA, AYERS GD, CHRISTOFANILI M, BROGLIO KR et al. Factors predicting additional disease in the axilla in patients with positive sentinel lymph nodes after neoadjuvant chemotherapy. Cancer 2008; 112: 2646-2654. http://dx.doi.org/10.1002/cncr.23481

[21] KOLARIK D. Breast cancer cell population - usage for implementation of the optimal mode of therapy. Predictive model. 21-6-2011. Charles University Prague, First Faculty of Medicine.

[22] KOLARIK D, LEVA JV, KREPELKA P, VERNER M, TRNKOVA $M$ et al. Breast cancer - how reliable are preoperative investigations. Actual Gyn 2012; 3: 21-26.

[23] KRAG D. NSABP B-32: Sentinel node resection without axillary dissection effective for node-negative breast cancer. ASCO 2010 Annual Meeting. 7.6.2010.

[24] ABDESSALAM SF, ZERVOS EE, PRASAD M, FARRAR, WB, YEE LD et al. Predictors of positive axillary lymph nodes after sentinel lymph node biopsy in breast cancer. Am J Surg 2001; 182: 316-320. http://dx.doi.org/10.1016/S00029610(01)00719-X

[25] CHU KU, TURNER RR, HANSEN NM, BRENNAN MB, BILCHIK A et al. Do all patients with sentinel node metastasis from breast carcinoma need complete axillary node dissection? Ann Surg 1999; 229: 536-541. http://dx.doi. org/10.1097/00000658-199904000-00013

[26] REYNOLDS C, MICK R, DONOHUE JH, GRANT CS, FARLEY DR et al. Sentinel lymph node biopsy with metastasis: can axillary dissection be avoided in some patients with breast cancer? J Clin Oncol 1999; 17: 1720-1726.

[27] TURNER RR, CHU KU, QI K, BOTNICK LE, HANSEN NM et al. Pathologic features associated with nonsentinel lymph node metastases in patients with metastatic breast carcinoma in a sentinel lymph node. Cancer 2000; 89: 574-581. http:// dx.doi.org/10.1002/1097-0142(20000801)89:3<574::AIDCNCR12>3.0.CO;2-Y

[28] WEISER MR, MONTGOMERY LL, TAN LK, SUSNIK B, LEUNG DY et al. Lymphovascular invasion enhances the prediction of non-sentinel node metastases in breast cancer patients with positive sentinel nodes. Ann Surg Oncol 2001; 8:145-129. http://dx.doi.org/10.1007/s10434-001-0145-y 